\title{
Gastroesophageal Reflux Disease (GERD): An Overview of Current Minimal-Invasive Treatment Potentials
}

\author{
Gottfried Lemperle ${ }^{1 *}$ and Stefan M Lemperle ${ }^{2}$ \\ ${ }^{1}$ Division of Plastic Surgery, University of California, USA \\ ${ }^{2}$ Ascent X Medical, Cornerstone Court, USA
}

*Corresponding author: Gottfried Lemperle, Division of Plastic Surgery, University of California, San Diego, USA.

To Cite This Article: Gottfried Lemperle. Gastroesophageal Reflux Disease (GERD): An Overview of Current Minimal-Invasive Treatment Potentials. Am J Biomed Sci \& Res. 2019 - 2(6). AJBSR.MS.ID.000619. DOI:_10.34297/AJBSR.2019.02.000619

Received: April 04, 2019 | Published: May 08, 2019

\begin{abstract}
GERD represents one of the most prevalent medical conditions in human society. Pharmaceutical and invasive surgical treatments of reflux are readily available with good results in most cases. However, medications don't cure GERD but rather decrease GERD symptoms, and may cause significant side effects with chronic use, while surgery has shown mixed results and is invasive and costly. These shortcomings have resulted in the development of various endo-luminal outpatient treatments for GERD as a more appealing alternative treatment option for gastroenterologists and their patients.
\end{abstract}

There remains a need for a safe and effective permanent injectable soft tissue bulking agent to complement the armamentarium of the GERD specialist and enables him to potentially cure GERD endoscopically. Collagen/PMMA implant (G125) has shown the most promising characteristics as an endoscopic' bulking agent' due to its proven tissue biocompatibility and persistence and seems to meet most characteristics of an 'ideal' bulking agent.

Introduction

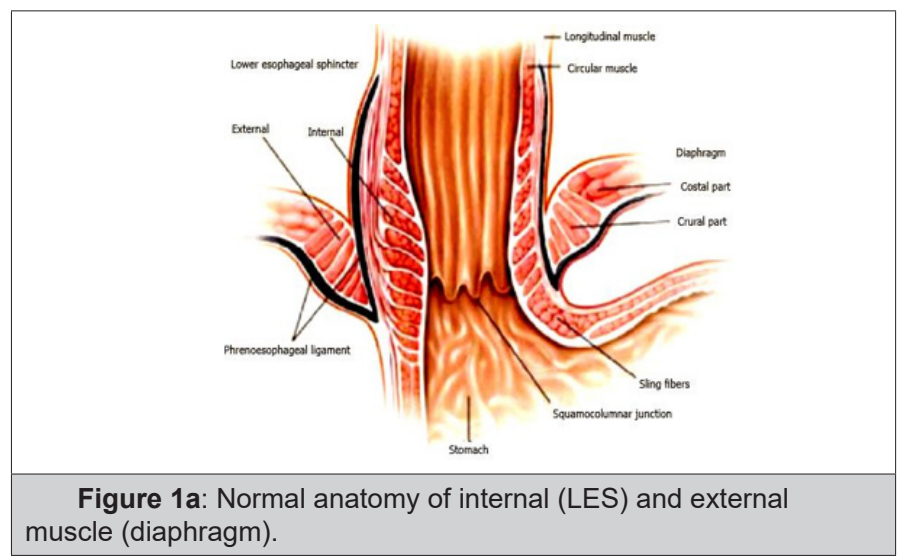

Gastroesophageal Reflux Disease (GERD) is defined as the presence of symptoms such as heartburn and regurgitation, and/ or tissue damage (i.e. erosive esophagitis) secondary to reflux of normal gastric contents into the esophagus (Figure $1 \mathrm{a} \& 1 \mathrm{~b}$ ). It is the second most common outpatient gastroenterological diagnosis in the United States, with a prevalence rate of $10-20 \%$ and an annual incidence of $0.38 \%-0.45 \%$ in the Western world [1]. In the
United States, 20\% (50 million Americans) of the adult population experience GERD-related symptoms weekly and 7\% (20 million Americans) daily [2]. An estimated 5-7\% of the world-population (circa 400 million people) suffer from GERD [3]. GERD significantly reduces health-related quality of life and imposes a marked economic burden on the healthcare system [4].

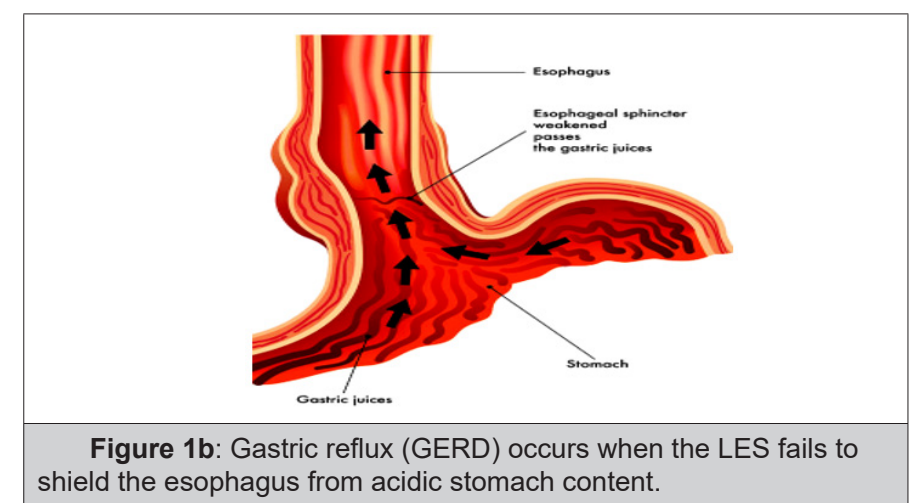

Studies show that frequent GERD symptoms are associated with esophageal adenocarcinoma, one of the deadliest forms of cancer 
[5] Years of chronic acid exposure can lead to Barrett's esophagus (Figure 2a \& 2b) - a pre-cancerous lesion caused by a metaplastic change from the normal squamous epithelium to "intestinalized" columnar epithelium in the distal esophageal lining -- which may eventually turn into highly malignant adenocarcinoma. About $12 \%$ of GERD sufferers develop Barrett's mucosa, which increases the risk for esophageal cancer by 40-times [3].

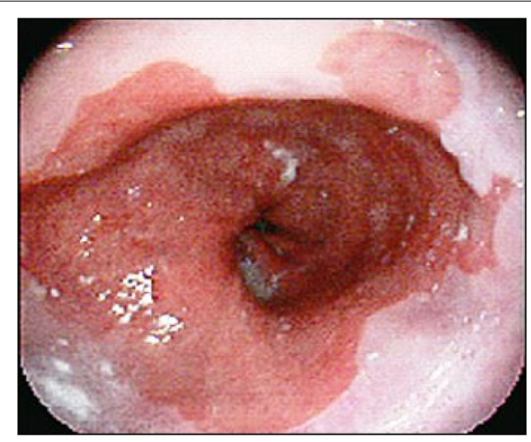

Figure 2a: GERD over years allows Barrett's metaplasia of the mucosa to develop.

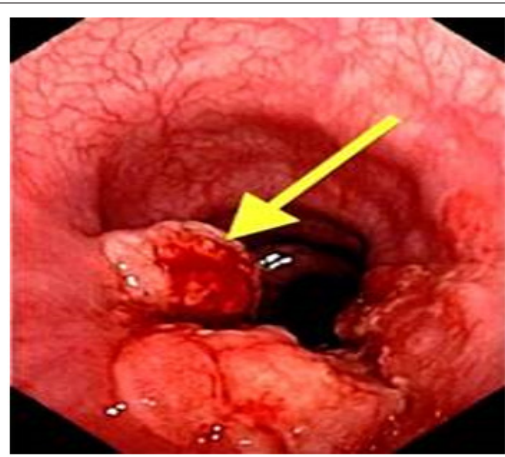

Figure $2 \mathrm{~b}$ : Potentially turn into malignant adenocarcinoma of the esophagus.

The incidence of esophageal adenocarcinoma (Figure 2b) the type linked with heartburn - has jumped five-fold in the past 30 years and has become the fastest growing cancer type in the U.S. Of all esophageal cancers, $80 \%$ are squamous cell carcinomas located in the middle and lower third of the esophagus. Although esophageal cancer remains relatively rare - in 2009 about 17,500 people were diagnosed in the U.S. with a 5-year survival rate of about $16 \%$ - it has become the seventh most common killer among men. [5]

The basic cause of GERD has been well characterized [6]. The underlying pathophysiology is a loss of integrity of the gastroesophageal barrier -- the 'lower esophageal sphincter' (LES) (Figure 1a). Loss of sphincter pressure in the LES results in reflux of gastric acid, occasionally even duodenogastric reflux of bile and digestive pancreatic enzymes.

\section{Present Treatments for GERD}

\section{Proton Pump Inhibitors (PPIs)}

Proton Pump Inhibitors (PPIs) are among the most commonly used agents for treatment of GERD, with brand-name PPIs (Nexium $\AA$, Protonix $\AA$, Prevacid $\AA$ ) comprising three of the top
11 most commonly prescribed medications in the United States and ranking second in monetary sales only to statins [7]. With the advent of over-the-counter Omeprazole $₫$ (Prilosec $₫$ ), selfdirected PPI therapy for GERD is now widely available and increases the potential for inappropriate use and overmedication. Pharmaceutical treatment of GERD has shown to be highly successful in relieving heartburn symptoms, with a relief rate for the four different generations of PPIs of 78-92\% with once-a-day therapy. However, chronic medication only achieves gastric acid 'suppression', and does not re-establish the anti-reflux barrier ('mucosal plug'), and therefore must be continued life-long. Following PPI discontinuation, $75-90 \%$ of patients have shown symptom relapse [8].

Mere symptom control with medication does not equal disease risk control, as GERD patients even under medical therapy are still at risk of developing esophageal adenocarcinoma ('silent killer') [9]. Another problem is that $10-30 \%$ of patients with proven GERD do not have full symptom relief, even with high doses of PPIs (refractory patients) [6], since PPIs do not completely suppress gastric acid production.

In addition, PPIs have been linked to various significant side effects [10-21] when used long-term, including possibly increased risks of heart attack [13-15], kidney failure [16], dementia [17], hip fractures [18-20], accelerated endothelial senescence [21] pneumonia and Vitamin B12 deficiency [11].

As a result, FDA is increasingly demanding proper risk disclosure on drug labels. According to FDA's news release dated May 25, 2010, the FDA's review of several studies found that "those at greatest risk for these fractures received high doses of PPIs or used them for one year or more." Accordingly, the FDA announced required label changes for PPIs, which disclose the increased risk of a hip, wrist or spine fracture linked to the use of PPIs [22].

\section{Laparoscopic or Open Surgery}

Since its initial description in 1956, the Nissen gastric fundoplication has become the gold standard surgical treatment for severe GERD (first 'open' Nissen fundoplication performed in 1955) to reduce long-term reliance on PPI use. While it is estimated that only $1 \%$ of patients with GERD receive a fundoplication [23], the procedure has shown to prevent both acid and non-acid reflux as documented by combined impedance and $\mathrm{pH}$-monitoring techniques [24]. Proper candidates, who meet the clinical criteria for successful anti-reflux surgery, should therefore consider Nissen fundoplication as a potential curative treatment for GERD.

However, in each individual candidate for anti-reflux surgery, the benefit of the procedure should outweigh the risk of potential short and long-term complications [2,7].

Nissen Fundoplication: Since the mid 1990ies, laparoscopic Nissen fundoplication (LNF) (Figures 3a \& 3b) has evolved into the standard surgical procedure to treat severe GERD There are more than 100,000 Nissen fundoplication's performed in the U.S. each year, and the number is rapidly increasing. Approximately 25,00030,000 procedures were performed in 1990 tripling to 80,000- 
90,000 in 2003) [25]. At an average procedure cost of approximately $\$ 25,000$, it represents an estimated overall annual cost burden of $\$ 2.5$ billion to the U.S. healthcare system and is usually performed on patients, who suffer from more advanced and complicated problems like large hiatal hernia, Barrett's esophagus, or refractory esophagitis--and should only be performed at Centers of Excellence due to its potentially severe side effects [7]. Those Centers have reported 10-year success rates of $85-90 \%$, even though $20-30 \%$ of patients continue to use their anti-secretory medications $[26,27]$.

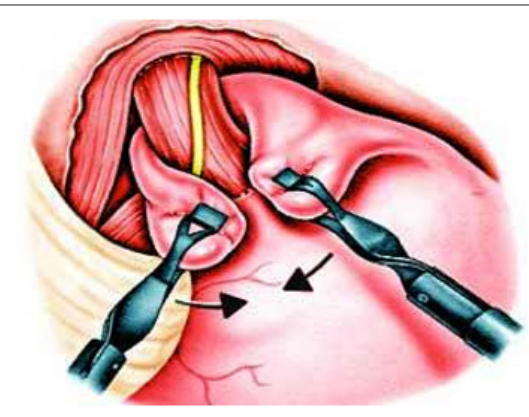

Figure 3a: NISSEN fundoplication: The fundus of the stomach is wrapped around the LES.

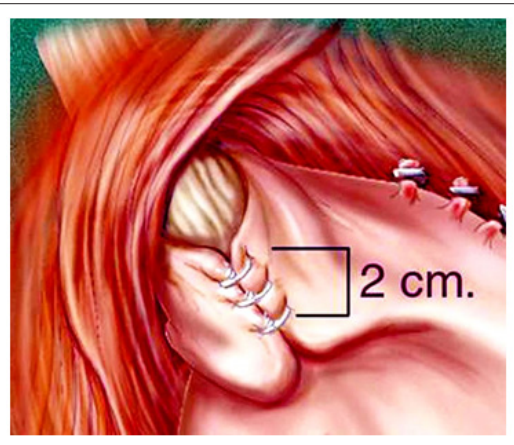

Figure $3 b$ : Stitched together (external cuff) to increase sphincter pressure.

Complications after gastric fundoplication may develop in up to $30 \%$ of patients and include dysphagia, dumping syndrome, inability to belch, diarrhea, and flatulence. Spechler et al. [27] reported that $62 \%$ of patients who underwent open reflux surgery were still taking acid suppressive drugs after 10 years.

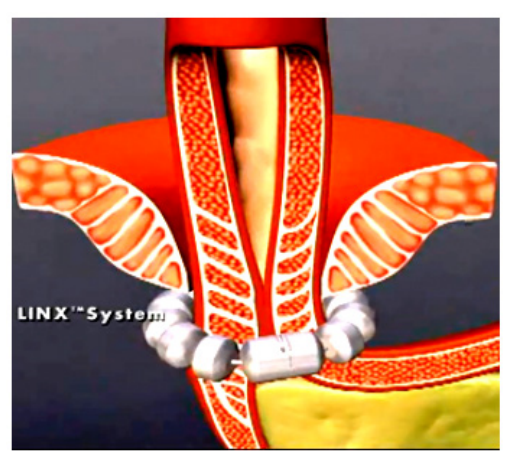

Figure 4a: The LINX® device consists of a 'bracelet' of interlinked magnetic titanium beads.

The LINX® Magnetic Sphincter Augmentation (MSA): The LINX® magnetic sphincter augmentation system (MSA) is a surgical technique with short-term evidence demonstrating efficacy in the treatment of medically refractory or chronic gastroesophageal reflux disease (GERD). This outer-esophageal 'bracelet' made of interlinked titanium beads with magnetic cores is implanted using a 4-port laparoscopic technique like that utilized for laparoscopic Nissen fundoplication to augment the Lower Esophageal Sphincter (Figure $4 \mathrm{a} \& 4 \mathrm{~b}$ ). The appropriate position of the MSA device is two centimeters proximal to the gastroesophageal (GE) junction, as determined laparoscopically by the gastric fat pad [23]. The device was first approved in Europe when Torax Medical received the CEMark in 2010.

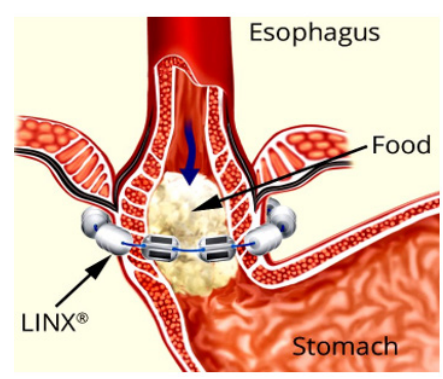

Figure 4b: opens under the pressure of a food bolus and closes at rest.

The magnetic beads are interconnected by titanium wires that allow each bead to move independently. This structure maintains the ring in the contracted form at rest and allows it to expand during the passage of a food bolus [23]. The circular force augments the barrier function of the LES and prevents the gastric juice from refluxing proximally. Higher pressure from swallowing temporarily breaks the magnetic bond between the beads to allow food passage, and once the food passes through the LES, the device returns to its resting state. LINX implantation requires laparoscopic surgery, general anesthesia, and hospitalization, and is exclusively performed by general surgeons.

Skubleny et al. [28] were the first to systematically review the literature and perform a meta-analysis comparing MSA to the Nissen fundoplication. Three primary studies identified a total of 688 patients, of whom 273 and 415 underwent Nissen fundoplication and MSA, respectively. MSA was statistically superior to LNF in preserving patient's ability to belch (95.2 vs $65.9 \%$ ) and ability to vomit (93.5 vs $49.5 \%$ ). There was no statistically significant difference between MSA and LNF in gas/bloating, postoperative dysphagia, and proton pump inhibitor (PPI) elimination.

Al-Mansour [28] reported dysphagia as the most common complication, with some degree of postoperative dysphagia observed in $34 \%$ to $79 \%$ of patients. In about $6.7 \%$ of patients, recurrent reflux symptoms or severe dysphagia can lead to MSA device removal [29]. In some patients the device was removed due to the need to obtain an MRI for unrelated problems.

Asti et al. [30] described the removal of 11 devices out of 164 implants $(6.7 \%)$ because of recurrent heartburn, dysphagia, or regurgitation. Furthermore, device erosion into the esophagus, migration, and device malfunction have also been described [3135]. 


\section{Endoluminal Therapies for GERD}

Ideally, GERD therapy should progress from the least-invasive to the most-invasive ('therapeutic ladder') to minimize risk and maximize benefit to patients. Natural orifice approaches to GERD and even natural orifice transluminal endoscopic surgery (NOTES) may help avoid intra-abdominal surgery. Therefore, according to the Society of American Gastrointestinal and Endoscopic Surgeons (SAGES), the following technologies warrant further development:

EsophyX ${ }^{\circledR}$ Transoral Incisionless Fundoplication (TIF): The EsophyX procedure (Endo Gastric Solutions Inc.) was developed to treat GERD trans-orally and without entering the abdominal cavity. The procedure reinforces the gastroesophageal junction by placating the upper portion of the stomach (fundus) around the gastroesophageal junction by approximately 270 degrees and securing it in place with special fasteners (Figures $5 a-5 c$ ). The EsophyX procedure is based on the same principles that have been shown effective with the Nissen fundoplication (external cuff concept). EsophyX received its 510k FDA clearance in 2007 and has since been used on a limited basis in approximately 20,000 patients [36].

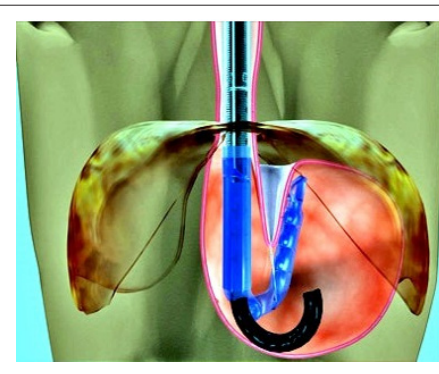

Figure 5a: The Esophy $X \circledR$ device pulls the gastric wall of the fundus around the lower esophagus to create a cuff by securing the plication with 12 non-absorbable staples.

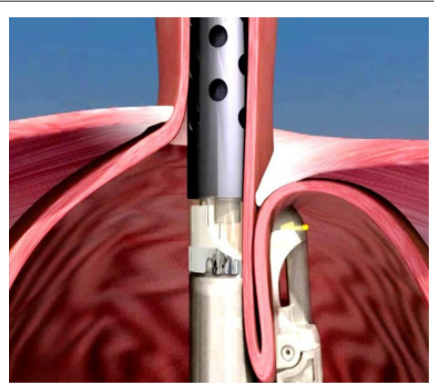

Figure 5b: The Esophy $X ®$ device pulls the gastric wall of the fundus around the lower esophagus to create a cuff by securing the plication with 12 non-absorbable staples.

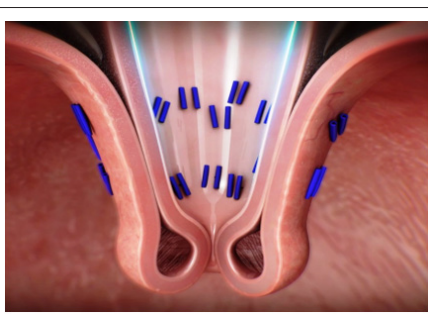

Figure 5c: The Esophy $X ®$ device pulls the gastric wall of the fundus around the lower esophagus to create a cuff by securing the plication with 12 non-absorbable staples.
The EsophyX procedure is not designed for patients with moderate to large hiatal hernias and its overall durability is shorter compared with laparoscopic fundoplication. However, the EsophyX procedure can be repeated, or a laparoscopic fundoplication can be performed if it doesn't work long-term. This procedure was initially evaluated in Europe, where two clinical trials demonstrated that $72.5 \%$ of patients were able to discontinue acid-suppressive medication [36]. The total satisfaction rate after TIF was about $69.15 \%$ in 6 months. The incidence of severe adverse events consisting of gastrointestinal perforation and bleeding was $2.4 \%$. The EsophyX procedure is predominantly performed by general surgeons and requires extensive training and involves a significant learning curve.

Stretta ${ }^{\circledR}$ Radio-Frequency: The Stretta radio-frequency (RF) device (originally marketed by CURON Medical) was developed to create permanent LES tightening via 'tissue contraction' through scar tissue formation after burning the mucosa around the LES (up to $85 \mathrm{C}$ heat for 1 minute). CURON ceased operations in November 2006 largely due to financial rea-sons after five perforations and two deaths were reported $[37,38]$.

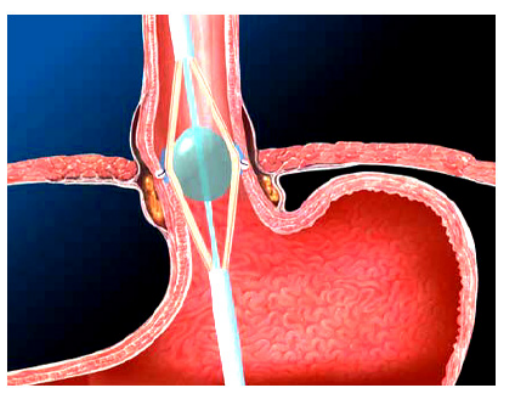

Figure 6a: Scarring with Stretta's radiofrequency (RF) procedure causes shrinkage of the LES.

In 2012, the Stretta RF technology was re-introduced to the market. The new Stretta Device (Mederi Therapeutics Inc.) is a non-endoscopic probe, which is positioned in the distal esophagus/ cardia via endoscopic landmark parameters (Figure 6a). Approximately 50 small radiofrequency cautery lesions are made in the cardia and distal $1 \mathrm{~cm}$ of squamous mucosa. These lesions cause focal fibrosis, lower esophageal sphincter manometric improvements and fewer transient LES relaxations. After some initial perforations and suboptimal outcomes, change of technique (mainly guide wire use and reduced number of cautery lesions) have resulted in an improved safety profile. Over 10,000 patients have been treated, but re-imbursement problems remain a limiting factor $[37,38]$.

In 2016, Das et al. [38] sought to answer the question whether the Stretta ${ }^{\circledR}$ procedure is as effective as the best medical and surgical treatments for patients with symptoms of gastroesophageal reflux disease (GERD). Looking at 140 Stretta-related papers, the authors conclude that further studies are required to determine the long-term efficacy of Stretta compared to the current best medical and surgical treatments.

EndoStim ${ }^{\circledR}$ LES Electrical Stimulation System: The Endostim Implantable Device (Endostim Inc.) for the lower 
esophageal sphincter (LES) functions like a cardiac pacemaker (Figure 6b). Bipolar stitch electrodes are laparoscopically placed in the LES and connected to an implantable pulse generator implanted subcutaneously in the anterior abdominal wall. [39]. Since May 2016, Endostim has been clinically evaluated in a U.S. FDA clinical trial in 110 patients (Clinical Trials.gov Identifier 'NCT02749071). So far, the authors concluded that LES-EST is safe and effective in controlling symptoms and esophageal exposure in GERD patients with incomplete response to PPIs. The observed results were comparable to those observed in PPI responders [39].

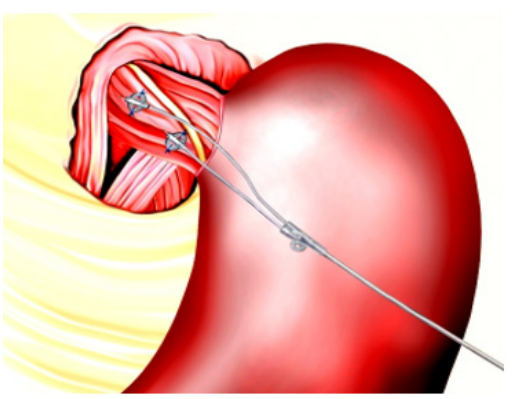

Figure 6b: The Endostim $₫$ Device stimulates the LES from an implanted electrical pulse generator.

\section{Discontinued Endoluminal Technologies}

Other promising mechanical devices for endo-luminal LEStightening had made it to the market in the early 2000's but failed to maintain effectiveness over longer periods because of the constant muscle movement of the esophagus and diaphragm.

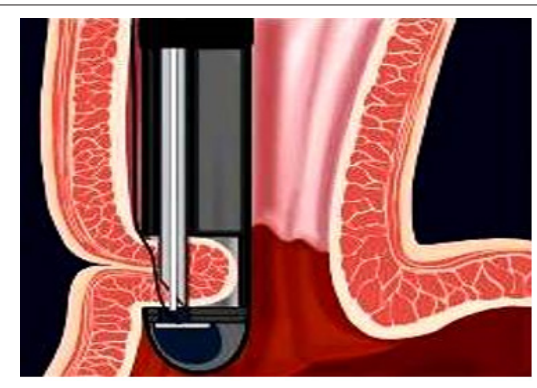

Figure 7a: The EndoCinch $\circledast$ device plicate the esophageal wall at the lower esophageal sphincter (LES).

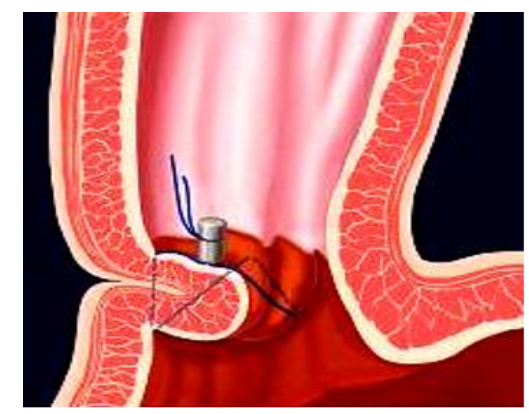

Figure $7 \mathrm{~b}$ : Unfortunately, the suture often cuts through the constantly moving LES.

a. EndoCinch $\AA$ Gastric Stapler: 'Endoluminal Gastroplasty' or ELGP, the suturing or stapling of the upper stomach or esophageal wall refers to devices such as EndoCinch® (Figure 7a \& 7b), Wilson-Cook Device $\AA$, and the Microvasive Gastric Stapler®. These modalities have not gained the anticipated market adoption for two reasons: First, the absence of objective improvementafter ELGP — no studies have shown improvement in LES pressure or length and grade of esophagitis. Second, the lack of durability: At one-year follow-up, a loss of 51\% plications in 60 patients after EndoCinch was reported. [40] The high incidence of repeat procedures precludes this technology from routine practice and EndoCinch is now mainly used for antiobesity surgery. Other technologies such as the full-thickness NDO-Plicator have failed to gain significant physician adoption due to cost and lack of 'ease-of-use' [41].

b. The Gatekeeper ${ }^{\circledR}$ Reflux Repair System (Medtronic) was designed for the endoscopic insertion of 4-6 hydrogel (HEMA) implants of $2.4 \mathrm{~mm}$ in diameter, which expand in situ to about the size of a gel cap upon contact with tissue moisture. Gatekeeper failed mainly because of implant extrusion and lack of proven efficacy [42].

c. $\quad$ Enteryx $®$ injectable bulking agent (Boston Scientific), a combination of a liquid polymer Ethyl vinyl-alcohol (EVOH) and a solvent that thickens to a rubber-like substance in situ, was discontinued because of loss of $>50 \%$ of implants due to mucosal sloughing [43].

d. Durasphere ${ }^{\circledR}$ (Carbon Medical), a suspension of carboncoated zirconium oxide microspheres of 220 - $500 \mu \mathrm{m}$ in diameter was tested in lower esophageal injections for GERD patients. Their carbon coating is very biocompatible and therefore actually prevents 'collagen encapsulation', which has resulted in sphere dislocation/migration and is therefore considered inadequate for GERD treatment [44].

e. Bovine collagen was used as the first dermal filler to treat facial wrinkles and scars for over 40 years (Zyderm ${ }^{\circledR}$ and Zyplast ${ }^{\circledR}$ ) [45]. However, the beneficial effects of collagen as a 'filler' agent proved to be rather short-lived, due to its absorption within three months.

A 1988 human pilot study by Connor and Lehman [46] in 10 medically intractable GERD patients initially showed excellent results after collagen injection 'bulking' of the LES, but collagen as a 'bulking' material was not further pursued, because of its dissatisfactory tissue persistence, and cost-prohibitive injection volume requirements (average $80 \mathrm{cc}$ ) due to partial extramural, rather than strictly submucosal material placement.

\section{New Potential Endoscopic Bulking Treatment for Gerd \\ PMMA Microspheres/Collagen Permanent Injectable Bulking Agent}

G125 is an experimental permanent injectable bulking agent to treat GERD. [47] The combination material consists of uniformly round and smooth polymethylmethacrylate (PMMA) microspheres $(125 \mu \mathrm{m})$, evenly suspended in a collagen 'carrier' to achieve permanent and strictly submucosal LES soft tissue augmentation via tissue bulking through a $23 \mathrm{G}$ needle. 
The bovine collagen carrier material prevents the microspheres from both migrating and agglomerating during the critical one-month tissue remodeling phase after injection. Via tissue engineering, permanent soft tissue augmentation is achieved through the stimulation of autologous human collagen encapsulation, accompanied by complete vascularization (fibrovascular tissue ingrowth).

This results in soft and pliable tissue bulking without the possibility of migration or dislocation of the implant. After the tissue remodeling process is complete, $80 \%$ of the final, mature tissue 'bulk' consists of human granulation tissue and only $20 \%$ of PMMA microspheres: it is a "living implant", which naturally bleeds when cut (Figure 8a \& 8b).
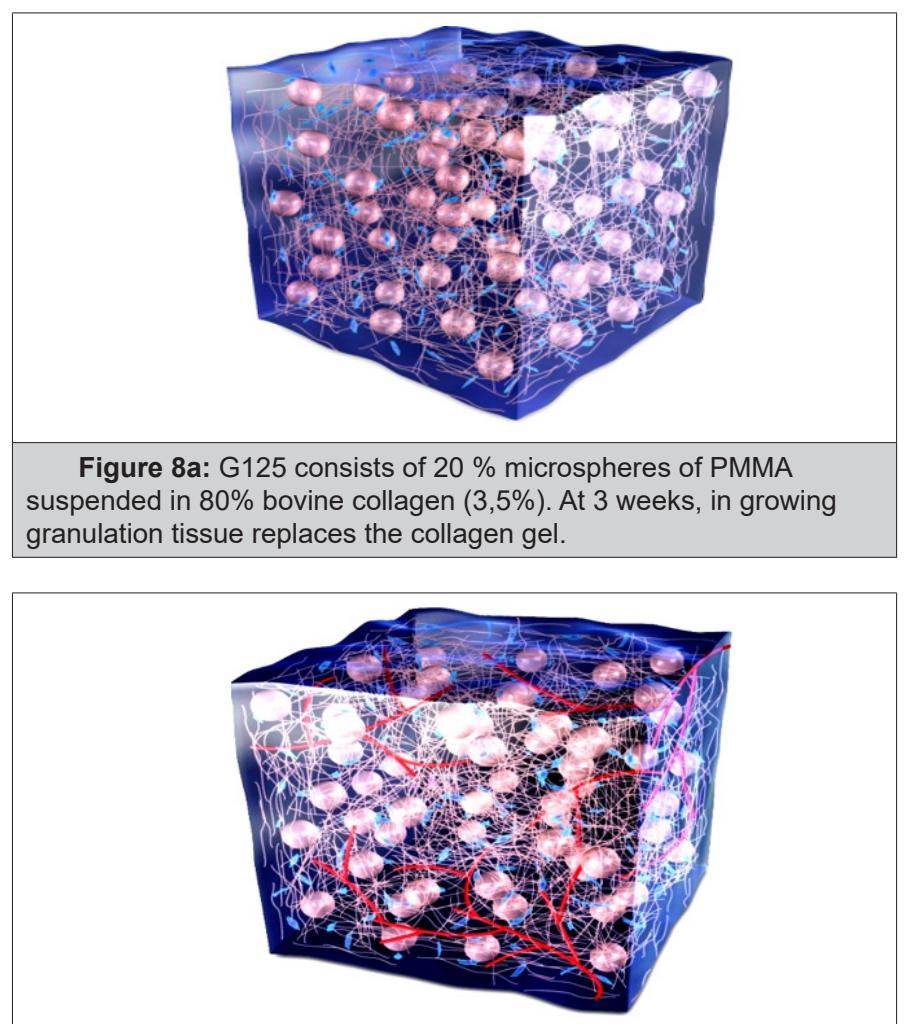

Figure 8b: At 3 months, the G125 implant is a "living" implant and bleeds when cut.

Since 1994, intradermal and subcutaneous implantation of $40 \mu \mathrm{m}$ PMMA microspheres suspended in bovine collagen have been clinically proven to be safe and effective in over 1 million patients worldwide, who received injections of permanent wrinkle fillers Artecoll ${ }^{\circledR}[48]$ or the only U.S. FDA-approved permanent wrinkle filler ArteFill $($ now Bellafill $@$ )[49-51].

\section{Proven Safety of Injectable PMMA Microspheres}

PMMA was first synthesized in Germany in 1928 and has since been widely used in the human body in form of bone cement, artificial dentures, intraocular lenses, cover for pacemakers, and in various other medical devices [52-54]. It is considered one of the safest biomaterials for human use and its excellent biocompatibility and lack of toxicity have been documented in many studies since 1940 [52].
(PMMA microspheres used in G125 are completely round and uniform and have a smooth surface) [53]. When injected into soft tissues, they cannot be broken down by enzymes, and if larger than $15 \mu \mathrm{m}$, they can still be phagocytosed but not transported away from the implantation site [54] (Figure 9a \& 9b).
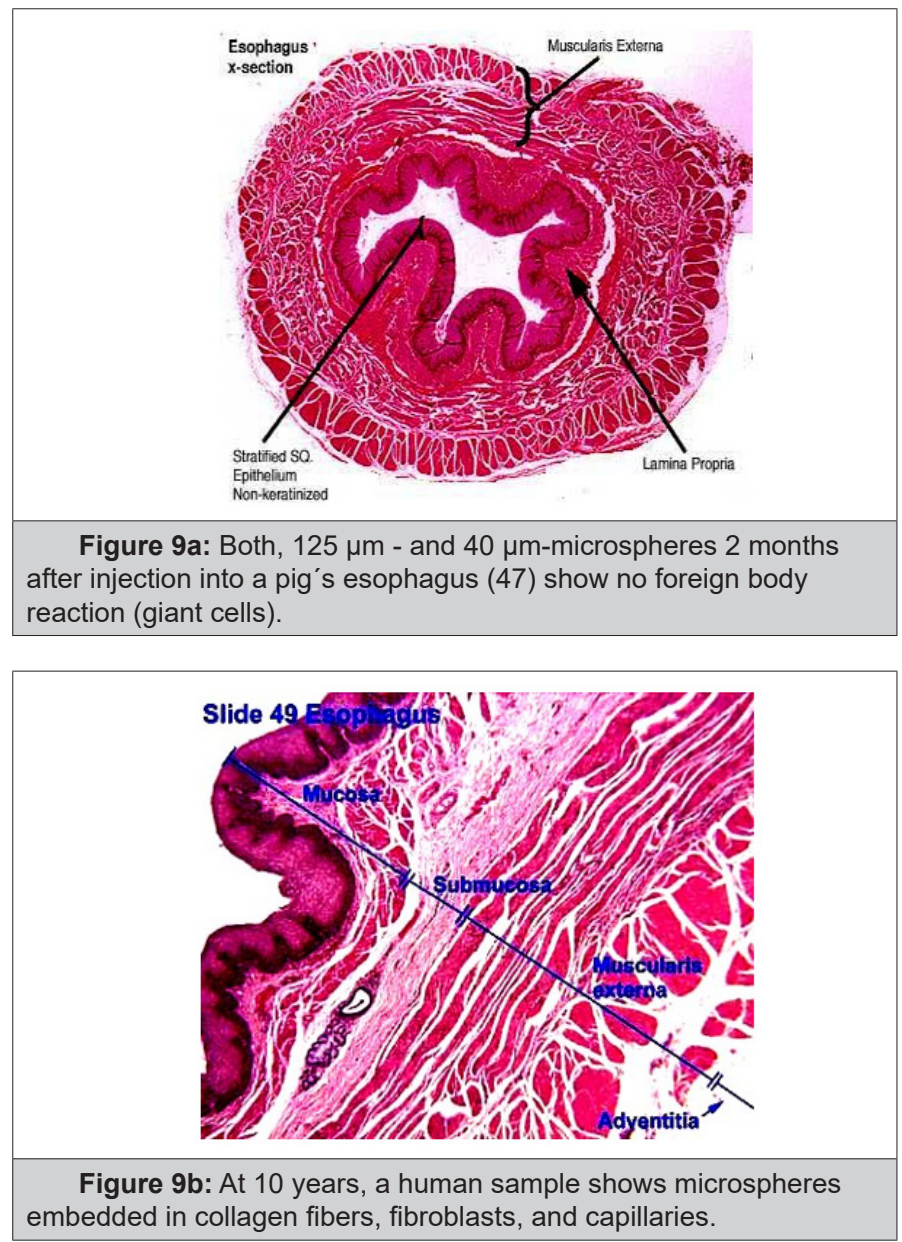

\section{G125 Permanent LES Bulking Agent for GERD}

In contrast to permanent dermal fillers containing $40 \mu \mathrm{m}$ PMMA microspheres for intradermal injections where the diameter of arterioles and venoles is smaller than $30 \mu \mathrm{m}$, injections applied for muscular sphincter reinforcement (urinary, esophageal or anal sphincter) require a minimum sphere size of $100 \mu \mathrm{m}$ because the surrounding venous plexus contains veins of up to a diameter of $80 \mu \mathrm{m}$ to prevent possible intravascular injections and transport to downstream organs including lung and liver [47,55-58].

The pre-clinical testing in mini swine has established $125 \mu \mathrm{m}$ as a safe particle size to avoid intra-vascular and intra-lymphatic transportation, in both lower esophageal and urinary sphincter injections [47,58] and G125 therefore consists of microspheres with a mean diameter of $125 \mu \mathrm{m}$ suspended in $3.5 \%$ bovine collagen gel (Figure 8a \& 8b). The PMMA spheres act as a 'scaffold' for autologous collagen deposition and microsphere encapsulation ('Soft Tissue Engineering').

Within approximately 1-3 months, the bovine collagen is completely absorbed and replaced with the patient 's own tissue 
(Figure 9a \& 9b). Each individual microsphere is encapsulated by 1-5 macrophages and permanently and safely anchored in the patient 's esophagus, preventing migration and dislocation.

\section{G125 Injection Technique into the LES}

A standard $70 \mathrm{~mm}$ endoscope (sigmoidoscope) with a working channel will be used to examine GERD patients for possible esophagitis or even Barrett's esophagus, which are contraindications for esophageal bulking. G125 will be injected strictly submucosally (Figure 10a \& 10b) in 2-4 mL aliquots, creating approximately 3 opposing blebs circumferentially 1-2 $\mathrm{cm}$ above the Z-line. The needle entry should generally be at a $10-$ $20^{\circ}$ angle and bulging mucosal blebs are instantly visible during injection ('mucosal plugs').

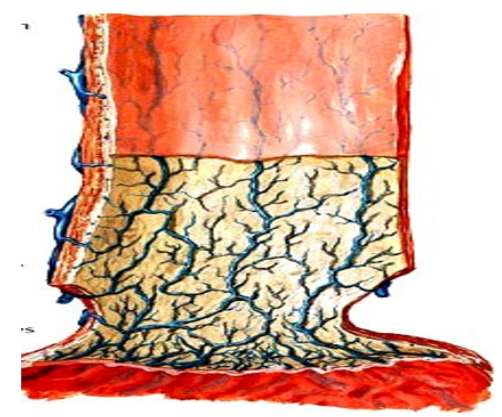

Figure 10a: A section through the esophagus shows its closure by mucosal folds; these folds can be augmented by submucosal G125 injections.

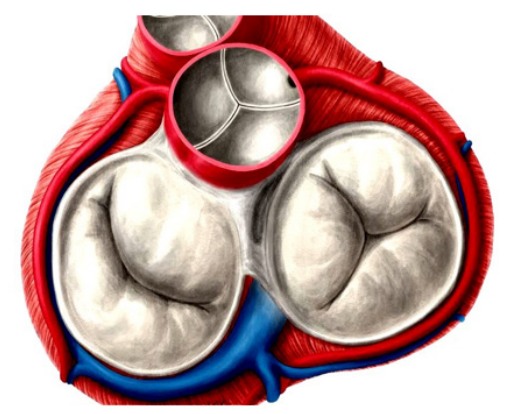

Figure 10b: The submucosal plane is clearly marked and easily accessible with a $23 \mathrm{G}$ needle tip.

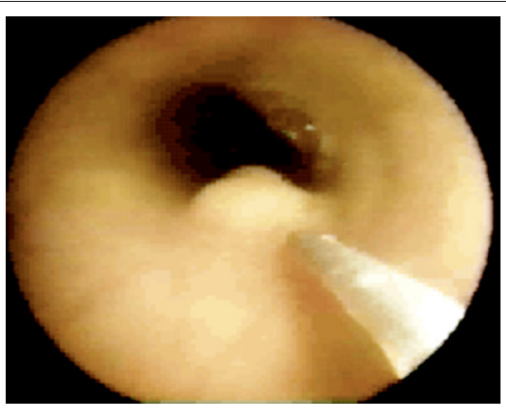

Figure 11a: Video images: The injector observes the growing submucosal G125-bleb and stops when one third of the lumen is filled. The needle tip has a stopper at $3 \mathrm{~mm}$ to prevent intra- and extra-muscular injections.

A properly angled stopper located $3 \mathrm{~mm}$ proximal of the needle tip is designed to prevent intra- and extramural injections. Photo and video documentation should be part of each endoscopy, and injections should only be performed if blebs visibly lift and separate the mucosa from the underlying muscle and create a bulge into the esophageal lumen (Figure 11a-11c).

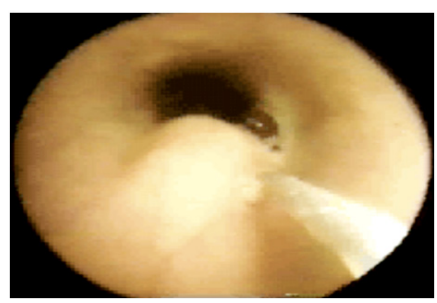

Figure 11b: Video images: The injector observes the growing submucosal G125-bleb and stops when one third of the lumen is filled. The needle tip has a stopper at $3 \mathrm{~mm}$ to prevent intra- and extra-muscular injections.

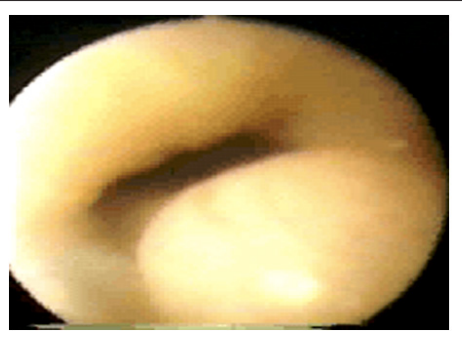

Figure 11c: Video images: The injector observes the growing submucosal G125-bleb and stops when one third of the lumen is filled. The needle tip has a stopper at $3 \mathrm{~mm}$ to prevent intra- and extra-muscular injections.

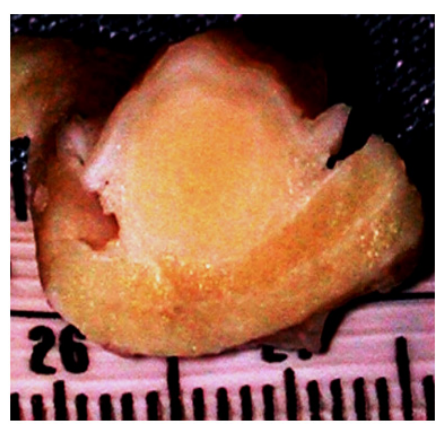

Figure 12a: Caution is advised to not inject into the most often visible longitudinal veins of $<90 \mu \mathrm{m}$ in diameter of the submucosal venous plexus.

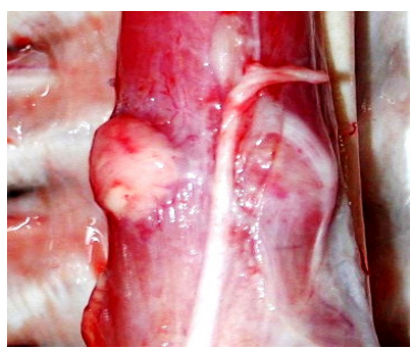

Figure 12b: The ideal closure of a loose LES is the MercedesBenz-star in form of 3 blebs simulating a tricuspid valve.

One must be cautious to avoid injections into any of the visible submucosal veins (Figure 12a). The result with G125 should be a 'Mercedes Benz Star' pattern, consisting of three opposing blebs, 
which create a complete, circumferential mucosal plug- like a tricuspid heart valve (Figure 12b).

The mucosa and muscularis between the blebs will continue to contract and expand when food is swallowed, allowing food passage into the stomach. Total injection volume and the number of blebs should be customized for each individual patient and anatomical situation, until complete mucosal adaptation is achieved. Since the G125 blebs consist of $80 \%$ autologous collagen after one month, they are soft and pliable and are not prone to ulceration and implant sloughing, as seen with Enteryx (Ethylvinyl-alcohol 'rubber'). [47].

\section{Pre-clinical Studies with PMMA Microsphere Injections in Pigs}

To date, four international research groups have investigated and confirmed the feasibility of PMMA microsphere injections to create a reflux barrier in the lower esophagus of pigs: [47,55-57].

In 2001, Feretis [55] reported on the injection of $100 \mu \mathrm{m}$ PMMA microspheres into the LES of mini swine. The microspheres were suspended in bovine gelatin and a total of 5-10 mL per animal was injected through an open laparotomy and gastrotomy. One month after injection, the microspheres remained located at the injection site in the cardia, grouped into clusters that were surrounded by connective tissue strands. In the specimens that were retrieved at 4,5 , and 6 months, the density of collagen fibers had increased, whereas the number of foreign body giant cells remained stable. No PMMA microspheres were found in lymph nodes, and lung and liver histology were normal.

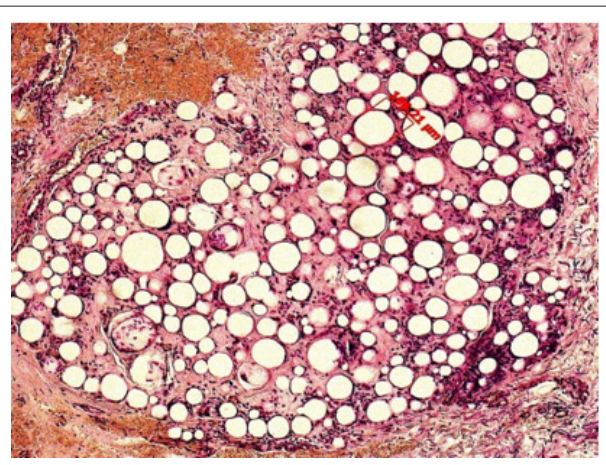

Figure 13a: Submucosal $\mathrm{G} 125$ implant of $2 \mathrm{~mL}$ in a pig and its cross section after 3 months.

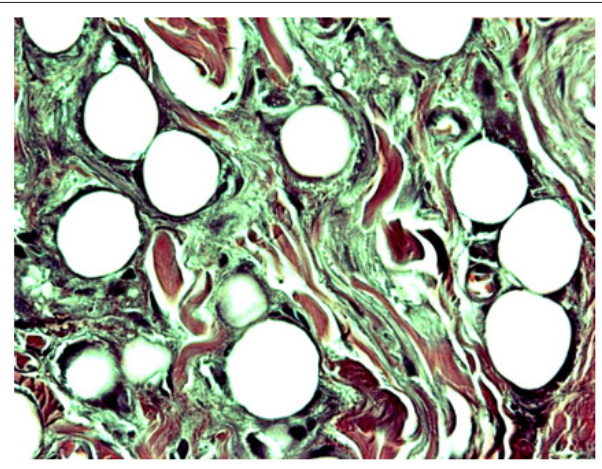

Figure 13b: Histology showed no signs of irritation or inflammation in any pig (47).
Kamler et al. [47] conducted two studies in mini swine to further address the local and remote tissue response to PMMA implant in the LES. During the Phase I study $40 \mu \mathrm{m}$ PMMA microspheres (G40) were endoscopically injected in the distal esophagus of eight healthy mini-swine. The implant sites showed persistent, completely healthy submucosal blebs (Figure 13a \& 13b) without any visible change or decrease in volume from baseline for 84 days, when the study was ended. Organ dissolution studies, however, showed some migration of $40 \mu \mathrm{m}$ microspheres into liver, lungs, and lymph nodes.

During a Phase II study, both $40 \mu \mathrm{m}$ (G40) and $125 \mu \mathrm{m}$ (G125) PMMA microspheres were injected separately, side-by-side, in the LES of seven healthy swine and sampling of organs for microsphere count was performed after eight days. Standardized organ dissolution again showed multiple G40 spheres in lymph nodes and lungs, but only one single G125 microsphere in the lung of one animal. The finding of a single $125 \mu \mathrm{m}$ microsphere in lung tissue from the Phase II study leads to the assumption that some of the extruded G125 material may have been aspirated at the end of the procedure while the endoscope was withdrawn. The study showed that G125 seems to be a safe and ideal injectable implant for submucosal esophageal bulking.

In an experimental study by Fornari [56], the LES of eight mini-pigs was injected endoscopically with four blebs of PMMA microspheres (1.9 - $72.4 \mu \mathrm{m}$ with a mean diameter of $40 \mu \mathrm{m})$. The augmentation of the anti-reflux barrier was measured by LES manometry and gas-tric yield volume and pressure, which were maintained during the six months study. Due to the high number of smaller PMMA microspheres contained in their implant, they detected microspheres in lymph nodes and concluded that larger beads must be used to provide a safe implant. Furthermore, since the high content of smaller beads $(<20 \mu \mathrm{m})$ bears the risk of granuloma formation [59], a product free of small, phagocytosable particles must be considered the new gold standard [54,59].

Another research group around Freitag [57] published a study in 18 large white pigs, which were examined after 28 days. Esophageal manometry and gastric yield measurements were performed before injection of $40 \mu \mathrm{m}$ PMMA microspheres and before euthanasia. There was a significant decrease in gastric yield pressure (GYP) from $10.7 \mathrm{~mm} \mathrm{Hg}$ versus $8.1 \mathrm{~mm} \mathrm{Hg}$ and of gastric yield volume (GYV) from $997 \mathrm{~mL}$ versus $393 \mathrm{~mL}$ after PMMA implantation, whereas resting LES pressure did not change significantly.

Lutfi et al. [60] concluded in their review article on endoscopic GERD treatments, that injection of PMMA is attractive in its simplicity and ease. They mention that the viscosity of the material can cause a technical challenge when injected through a long needle or catheter.

This challenge has been resolved with the development of a special G125 Injection Apparatus (Elongated Flexible Syringe). The endoscopic injection technique has also been refined, using a 23G needle with a stopper to allow precise, strictly submucosal injections under direct vision [61]. 


\section{Human Pilot Study with $100 \mu$ m PMMA Microspheres for GERD}

Bulking of the LES with PMMA microspheres in a human pilot study was first performed by Feretis et al. [62], and no serious adverse events were reported. A total of 10 patients, who were PPI-dependent with refractory GERD, were treated. Injections of a suspension of PMMA microspheres of $100 \mu \mathrm{m}$ in bovine gelatin were injected into the submucosa of the lower esophagus, $1-2 \mathrm{~cm}$ proximal to the Z-line, through a shortened injection catheter using a $21 \mathrm{G}$ needle. Patients received 5-6 injections in different sites until the bulking of the esophageal wall resulted in close approximation. A mean volume of $32 \mathrm{~mL}$ was injected.

The primary outcome variable assessed was the severity of GERD symptoms before and after implantation, using a graded scale for heartburn, regurgitation, pain, and dysphagia. The results demonstrated a significant decrease in severity of the GERD symptom score in 9 of 10 patients (from 12.2 to 6.2).

Feretis et al. [62] reported their subsequent evaluation at a median time of 14.5 months after implantation. At this later followup, 7 out of 10 patients were completely off medication at least 12 months after implantation and the mean symptom severity score was still significantly decreased. Endoscopic examination at study entry confirmed that five patients had GERD-associated erosive esophagitis. In the latest follow-up evaluation, three of these five patients showed evidence of healing of the esophageal lesions. Endoscopic ultrasound immediately post injection verified the submucosal position of the implants. At the initial follow-up examination, PMMA particles remained in all sites of implantation in all 10 patients.

\section{Potential Complications with G125 Esophageal Bulking Procedure}

a. Endoscopy itself bears certain well-known risks during sedation, which are not discussed in this paper.

b. Intravenous injection: As with any injection procedure, inadvertent intravenous placement of small amounts of G125 material may occur. In general, the vertical run of the few submucosal veins in the esophagus can be well visualized endoscopically and thus avoid-ed during injection (Figure 12a). The injector must focus on the rising bleb under direct vi-sion to make sure he is injecting strictly into the submucosal space. If no bleb arises, one must stop immediately and reposition the needle correctly. Small amounts of G125, even $1 \mathrm{~mL}$, would not cause harm to the lung or liver. [62]

c. The veins of the distal third of the esophagus are arranged in three plexus and drain into the chest veins and portal circulation. The veins of the mucosal plexus and plexus in the tunica muscularis propria have diameters between 35-40 $\mu \mathrm{m}$. There are a few visible veins of the submucosal plexus which exceed $80 \mu \mathrm{m}$ in diameter [47] (Figure 12a).

d. Extramural injections: Theoretically, G125 material can be injected too deep, e.g. into the sphincter muscle and be transported outside under the adventitia of the esophagus
(Figure 13). These, as well as injections into the mediastinum will not harm the patient, as has been demonstrated with collagen [46] and PMMA inadvertently injected in amounts of 10-100 mL outside the LES sphincter-- but without clinical consequences. Wrong-ful placement of G125 can be avoided via a stopper at $3 \mathrm{~mm}$ proximal of the needle tip.

e. Bleeding from esophageal veins can occur during and after the injection, if the vessel wall is ruptured, however in the absence of significant coagulopathy, any significant bleeding is unlikely.

f. Post-injection dysphagia: Patients may experience transient dysphagia until their esophagus has adapted to the newly created 'narrowing' of its lumen and increased sphincter pressure. Patients may also experience transient minor chest pain and gas-bloat, which usually resolve spontaneously [62]. Even though infection at the G125 implant site is un-likely, based on our pre-clinical testing in mini-swine, a peri-implantation antibiotic regi-men will be applied per study protocol.

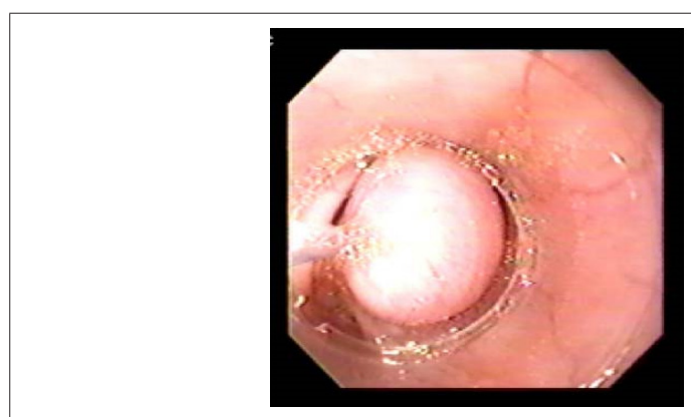

Figure 14a: If necessary, the G125 implant can easily be removed with an electrical sling.

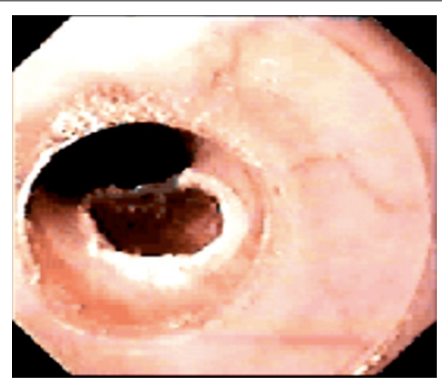

Figure 14b: The mucosal defect heals within a few days.

g. Implant removal: In case of persistent dysphagia after G125 implantation, the first line treatment is endoscopic dilation, which has shown to resolve the problem in most patients. [63] In our animal studies, G125 could be safely removed by endoscopic mucosal excision via snare cauterization in the rare instance that some or all the G125 implant would require removal (Figure 14a \& 14b). Evidence on strictures after mucosal resection strongly shows that strictures occur if more than $50 \%$ of the circumference of the lumen is removed. Mucosal resection strictures, if they occur, are usually easily/ easily dilated. Since G125 implants will be administered in a stepwise fashion, it is unlikely that a large "overdose" will occur and require removal. 


\section{Conclusion}

Based on the outcomes of the first human pilot study using $100 \mu \mathrm{m}$ PMMA microspheres and pre-clinical studies testing G125 in mini swine, it appears that injections of $125 \mu \mathrm{m}$ microspheres are safe for human use in the LES.

Joel Richter M.D. has stated that "the optimal treatment approach for GERD is one using the natural route through the esophageal lumen that does not invade the abdominal or thoracic cavity to repair the incompetent LES. This is where endoscopic treatments come into play "Microsphere injections avoiding any metallic implant, staples, or tissue damage via radio frequency, presents a superior technology solution and worthwhile goal to pursue in order to avoid potential long-term side effects caused by implant failure. In short, the more natural the implant, the better.

\section{The 'ideal' bulking agent for GERD (adapted from Rupp} and Lehman [64]:

a. Low viscosity (easy to inject through a modified 23-gauge sclerotherapy needle)

b. Biologically inert (non-carcinogenic, hypoallergenic, nonimmunogenic)

c. Low side effect profile

d. Non-biodegradable

e. High persistence at implantation site

f. Capable of resisting mechanical strain

g. Favorable plasticity

h. Favorable elasticity

i. No adverse effect on adjacent musculature

j. Easily removable without permanent tissue damage in case of over-injection

k. Cost-effective

\section{Best candidates for G125 treatment are the following} [65]:

a. Patients with impaired GERD-related quality of life due to persistent heartburn de-spite escalating doses of PPIs

b. Patients who have residual regurgitation without heartburn while on PPIs

c. Patients with objectively demonstrable GERD who are symptomatic because they cannot tolerate PPIs (2\% of PPI users)

d. Patients who desire to stop drug therapy, fearful of longterm sequelae

e. Patients who have demonstrated an abnormal 24-Hour $\mathrm{pH} \geq 4 \%$ time with $\mathrm{pH} \leq 4.0$

f. Patients with a baseline GERD-HRQL heartburn score of $\leq 11$ on PPI and $\geq 20$ off PPI

\section{Criteria for probable exclusion [66]:}

a. Extensive Barrett's Esophagus $(>2 \mathrm{~cm})$

b. Esophagitis (L.A. Classification Grades C or D)

c. Large hiatal hernia $(>3 \mathrm{~cm})$

d. Esophageal strictures

e. Portal hypertension and esophageal varicosis

Poor candidates for endoscopic therapies are mainly those with refractory GERD, who have a large, fixed, sliding hiatal hernia ( $>3 \mathrm{~cm}$ long), that technically prohibits the application of a bulking agent. Those patients will require surgery. More than $90 \%$ of PPI refractory patients have little or no esophagitis, and their mucosa will certainly hold the G125 implant.

Approximately $50 \%$ of PPI refractory patients have a hiatal hernia of greater than $2 \mathrm{~cm}$, and most clinical studies limit to $3 \mathrm{~cm}$ or less. Barrett's mucosa will be a relative contraindication in about $5 \%$ of patients. Other limiting factors such as strictures are very infrequent.

\section{Summary}

Natural orifice approaches to GERD and even natural orifice transluminal endoscopic surgery (NOTES) may offer further benefits, especially after the discontinuation of Enteryx ${ }^{\circledR}$ bulking agent and the cessation of the clinical development of the Gatekeeper@ system $[42,43]$.

If proven safe and effective in the long-term, endoscopic treatments could revolutionize the management of GERD and potentially correct this prevalent condition definitively. Currently, the most promising technology for a safe and effective 'bulking agent' remains the PMMA/collagen implant, as it has already demonstrated positive results in both, pre-clinical [47,55-58] and a clinical pilot study [67]. Understandably, the development of modern bulking agents is more advanced in the field of female stress urinary incontinence (SUI) [68,69].

Most patients, who experience severe GERD may benefit from G125 as a first-line, easy-to-perform, and cost-effective endoscopic outpatient procedure, either alone or in conjunction with other treatment modalities such as PPIs and/or surgery [70,71].

If clinical outcomes with G125 can establish long-term safety and efficacy, the technology, due to its simplicity, minimalinvasiveness, and cost-effectiveness, has the potential to enjoy a high adoption rate among gastroenterologists, who currently have no curative treatment modality available, and could therefore become the leader among outpatient treatment options for GERD $[72,73]$.

\section{References}

1. Dent J, El-Serag HB, M-A Wallander, S Johansson (2005) Epidemiology of gastro-oesophageal reflux disease: A systematic review. 54(5): 710-717.

2. Fass R (2012) Alternative therapeutic approaches to chronic proton pump inhibitor treatment. Clin Gastroenterol Hepatol 10(4): 338-345. 
3. William D Chey (2007) The global GERD epidemic: Definitions, demographics, and the clinical implications of changing population trends. Medscape Education.

4. Sandler RS, Everhart JE, Donowitz M, Adams E, Cronin K, et al. (2002) The burden of selected digestive diseases in the United States. Gastroenterology 122(5): 1500-1511.

5. Rubinstein JH, Taylor JB (2010) Meta-analysis: the association of oesophageal adenocarcinoma with symptoms of gastro-esophageal reflux. Aliment Pharmacol Ther 32(10): 1222-1227.

6. Souza RF (2016) From reflux esophagitis to esophageal adenocarcinoma Dig Dis 34(5): 483-490.

7. Smith CD (2010) New Developments in esophageal surgery. Gastrointest Endoscopy Clin N Am 20(1): 139-145.

8. Boghossian TA, Rashid FJ, Thompson W, Welch V, Moayyedi P, et al. (2017) Deprescribing versus continuation of chronic proton pump inhibitor use in adults. Cochrane Database Syst Rev 3: CD011969.

9. Tara Parker-Pope (2005) The hidden dangers of heartburn: How a common health problem is quietly becoming an unsuspected killer Personal Health the Wall Street Journal.

10. Freedberg DE, Kim LS, Yang YX (2017) The risks and benefits of long-term use of proton pump Inhibitors: Expert review and best practice advice from the American Gastroenterological Association. Gastroenterology 152(4): 706-715

11. Abramowitz J, Thakkar P, Isa A, Truong A, Park C, et al. (2016) Adverse event reporting for proton pump inhibitor therapy: An overview of systematic reviews. Otolaryngol Head Neck Surg 155(4): 547-554.

12. Heidelbaugh JJ, Goldberg KL, John M Inadomi (2009) Adverse risks associated with proton pump inhibitors: A systematic review. Gastroenterol Hepatol 5(10): 725-734.

13. Shah NH, LePendu P, Bauer-Mehren A, Ghebremariam YT, Iyer SV et al. (2015) Proton pump inhibitor usage and the risk of myocardial infarction in the general population. PLoS One 10(6): 0124653.

14. Ghebremariam YT, LePendu P, Lee JC, Erlanson DA, Slaviero A, et al. (2013) Unexpected effect of proton pump inhibitors: Elevation of the cardiovascular risk factor asymmetric dimethylarginine. Circulation 128(8): 845-853

15. Xie Y, Bowe B, Li T, Xian H, Yan Y, et al. (2017) Risk of death among users of proton pump inhibitors: a longitudinal observational cohort study of United States veterans. BMJ Open 7(6): e015735.

16. Lazarus B, Chen Y, Wilson FP, Sang Y, Chang AR, et al. (2016) Proton pump inhibitor use and the risk of chronic kidney disease. JAMA Internal Medicine 176(2): 238-246.

17. Gromm W, von Holt K, Thomé F, Broich K, Maier W, et al. (2016) Association of proton pump inhibitors with risk of dementia: A pharmaco-epidemiological claims data analysis. JAMA Neurology 73(4): 410-416.

18. Yang YX, Lewis JD, Epstein S, Metz DC (2006) Long-term proton pump inhibitor therapy and risk of hip fracture. JAMA 296(24): 2947-2953.

19. Vestergaard P, Rejnmark L, Mosekilde L (2006) Proton pump inhibitors, histamine $\mathrm{H} 2$ receptor antagonists, and other antacid medications and the risk of fracture. Calcif Tissue Int 79(2): 76-83.

20. Targownik LE, Lix LM, Metge CJ, Prior HJ, Leung S, et al. (2008) Use of proton pump inhibitors and risk of osteoporosis-related fractures. CMAJ 179(4): 319-326

21. Yepuri G, Sukhovershin R, Timo Z, Michael Petrascheck, Yohannes T Ghebre, et al. (2016) Proton pump inhibitors accelerate endothelial senescence. Circulation Research 118(12): e36-e42.

22. (2011) FDA Drug Safety Communication: Possible increased risk of fractures of the hip, wrist, and spine with the use of proton pump inhibitors.
23. Al Mansour, Perry KA, Jeffrey W Hazey (2017) The current status of magnetic sphincter augmentation in the management of gastroesophageal reflux disease. Ann Laparosc Endosc Surg 2: 146.

24. del Genio G, Tolone S, del Genio F, Rossetti G, Brusciano L, et al. (2008) Total fundoplication controls acid and nonacid reflux: evaluation by pre-and postoperative 24-h pH-multichannel intraluminal impedance. Surgical endoscopy 22(11): 2518-2523.

25. Peters JH (2006) Laparoscopic Treatment of gastro-esophageal reflux. In: Talamini M (Ed.), Advanced Therapy in Minimally Invasive Surgery. BC Decker Inc Hamilton Ontario pp. 111-120.

26. Du X, Wu JM, Hu ZW, Wang F, Wang ZG, et al. (2017) Laparoscopic Nissen (total) versus anterior $180^{\circ}$ fundoplication for gastro-esophageal reflux disease: A meta-analysis and systematic review. Medicine Baltimore 96(37): e8085.

27. Spechler SJ, Lee E, Ahnen D, Goyal RK, Hirano I, et al. (2001) Long-term outcome of medical and surgical therapies for gastroesophageal reflux disease: follow-up of a randomized controlled trial. JAMA 285(18): 2331-2338.

28. Skubleny D, Switzer NJ, Dang J, Gill RS, Shi X, et al. (2017) LINX® magnetic esophageal sphincter augmentation versus Nissen fundoplication for gastroesophageal reflux disease: a systematic review and meta-analysis. Surg Endosc 31(8): 3078-3084.

29. Harnsberger CR, Broderick RC, Fuchs HF, Martin Berducci, Catherine Beck, et al. (2015) Magnetic lower esophageal sphincter augmentation device removal. Surg Endosc 29(14): 984-986.

30. Asti E, Bonitta G, Lovece A, Lazzari V, Bonavina L, etal. (2016) Longitudinal comparison of quality of life in patients undergoing laparoscopic Toupet fundoplication versus magnetic sphincter augmentation: Observational cohort study with propensity score analysis. Medicine (Baltimore) 95(30): e4366.

31. Bielefeldt K (2016) Adverse Events After Implantation of a Magnetic Sphincter Augmentation Device for Gastroesophageal Reflux. Clin Gastroenterol Hepatol 14(10): 1507-1508.

32. Lipham JC, Taiganides PA, Louie BE (2015) Safety analysis of first 1,000 patients treated with magnetic sphincter augmentation for gastroesophageal reflux disease. Dis Esophagus 28(4): 302-311.

33. Siddiqi S, Ullah S, Pervin N (2017) LINX Reflux Management System - Is it a permanent solution for GERD? J Pak Med Assoc 67(4): 650-651.

34. Asti E, Siboni S, Lazzari V, Bonitta G, Sironi A, et al. (2017) Removal of the magnetic sphincter augmentation device: Surgical technique and results of a single-center cohort study. Ann Surg 265(5): 941-945.

35. Reynolds JL, Zehetner J, Nieh A, Bildzukewicz N, Sandhu K, et al. (2016) Charges, outcomes, and complications: a comparison of magnetic sphincter augmentation versus laparoscopic Nissen fundoplication for the treatment of GERD. Surg Endosc 30(8): 3225-3230.

36. Huang X, Chen S, Zhao H, Zeng X, Lian J, et al. (2017) Efficacy of transoral incisionless fundoplication (TIF) for the treatment of GERD: a systematic review with meta-analysis. Surg Endosc 31(3): 1032-1044.

37. Arts J, Sifrim D, Rutgeerts P, Lerut A, Janssens J, et al. (2007) Influence of radiofrequency energy delivery at the gastroesophageal junction (the Stretta procedure) on symptoms, acid exposure, and esophageal sensitivity to acid perfusion in gastroesophageal reflux disease. Dig Dis Sci 52(9): 2170-2177.

38. Das B, Reddy M, Khan OA (2016) Is the Stretta procedure as effective as the best medical and surgical treatments for gastro-oesophageal reflux disease? A best evidence topic. Int J Surg 30: 19-24.

39. Soffer E, Rodriguez L, Rodriguez P, Gómez B, Neto MG, et al. (2016) Effect of electrical stimulation of the lower esophageal sphincter in gastroesophageal reflux disease patient's refractory to proton pump inhibitors. World J Gastrointest Pharmacol Ther 7(1): 145-155. 
40. Schiefke I, Zabel Langhennig A, Neumann S, Feisthammel J, Moessner J, et al. (2005) Long term failure of endoscopic gastroplication (EndoCinch). Gut 54(6): 752-758.

41. von Renteln D, Schiefke I, Fuchs KH, Raczynski S, Philipper M, et al. (2009) Endoscopic full-thickness plication for the treatment of gastroesophageal reflux disease using multiple Plicator implants: 12-month multicenter study results. Surg Endosc 23(8): 1866-1875.

42. Fockens P, Cohen L, Edmundowicz SA, Kenneth Binmoeller, Richard I Rothstein, et al. (2010) Prospective randomized controlled trial of an injectable esophageal prosthesis versus a sham procedure for endoscopic treatment of gastroesophageal reflux disease. Surg Endosc 24(6): 1387-1397.

43. Wong RF, Davis TV, Peterson KA (2005) Complications involving the mediastinum after injection of Enteryx for GERD. Gastrointest Endosc 61(6): 753-756.

44. Ganz RA, Fallon E, Wittchow T, Klein D (2009) A new injectable agent for the treatment of GERD: Results of the Durasphere pilot trial. Gastrointest Endosc 69(2): 318-323.

45. Knapp TR, Kaplan EN, Daniels JR (1977) Injectable collagen for soft tissue augmentation. Plast Reconstr Surg 60(3): 398-408.

46. Connor KW, Lehman GA (1988) Endoscopic placement of collagen at the lower esophageal sphincter to inhibit gastroesophageal reflux: a pilot study of 10 medically intractable patients. Gastrointest Endoscopy 34(2): 106-112.

47. Kamler J, Lemperle G, Lemperle SM, Lehman GA (2010) Endoscopic lower esophageal sphincter bulking for the treatment of GERD: Safety evaluation of injectable polymethylmethacrylate microspheres in miniature swine. Gastrointest Endosc 72(2): 337-342.

48. Li D, Luo SK, Wang YC, Lemperle G (2017) Facial volume restoration with permanent dermal filler Artecoll-4 in Chinese women. Facial Plast Surg 33(5): 537-544.

49. Lemperle G, Knapp TR, Sadick NS, Lemperle SM (2010) ArteFill permanent injectable for soft tissue augmentation: 1. Mechanism of action and injection techniques. Aesthet Plast Surg 34(3): 267-272.

50. Cohen S, Berner C, Busso M, Clopton P, Hamilton D, et al. (2007) Fiveyear safety and efficacy of a Novel polymethyl-methacrylate aesthetic soft tissue filler for the correction of nasolabial folds. Dermatol. Surg 33(2): S222-S230.

51. Joseph JH, Eaton LL, Cohen SR (2015) Current Concepts in the Use of Bellafill. Plast Reconstr Surg 136(5): 171S-179S.

52. Frazer RQ Byron RT, Osborne PB, West KP (2005) PMMA: An Essential Material in Medicine and Dentistry. Journal of Long-Term Effects of Medical Implants 15(6): 629-639.

53. Lemperle G, Ott H, Charrier U, Hecker J, Lemperle M (1991) PMMA microspheres for intradermal implantation Part I Animal Research. Ann Plast Surg 26(1): 57-63.

54. Lemperle G, Neugebauer P, Kernke R, Lerche K H, Lemperle SM (2017) Microspheres for cosmetic and medical injections must be free of phagocytosable microparticles under 20 microns. Biomed J Sci \& Tech Res 1:1-5.

55. Feretis C, Benakis P, Dimopoulos C, Dailianas A, Filalithis P, et al. (2001) Endoscopic implantation of Plexiglas microspheres for the treatment of GERD Gastrointest Endosc 53(4): 423-426.

56. Fornari F, Freitag CP, Duarte ME, Kruel CR, Thomé PR, et al. (2009) Endoscopic augmentation of the esophagogastric junction with polymethylmethacrylate: durability, safety, and efficacy after 6 months in mini-pigs. Surg Endosc 23(11): 2430-2437.

57. Freitag CP, Kruel CR, Duarte ME, Sanches PR, Thomé PR, et al. (2009) Endoscopic implantation of polymethylmethacrylate augments the gastroesophageal antireflux barrier: a short-term study in a porcine model. Surg Endosc 23(6): 1272-1278.

58. Lemperle G, Lappin PB, Stone C, Lemperle SM (2011) Urethral bulking with polymethylmethacrylate microspheres for stress urinary incontinence: Tissue persistence and safety studies in miniswine. Urology 77(4): 1005.e1-1005.e7.

59. Lemperle G, Gauthier-Hazan N, Wolters M, Eisemann-Klein M, Zimmermann U, et al. (2009) Foreign body granulomas after all injectable dermal fillers: Part 1 Possible causes. Plast Reconstr Surg 123(6): 1842-1863.

60. Lutfi RE, Torquati A, Richards WO (2004) Endoscopic treatment modalities for gastroesophageal reflux disease. Surg Endosc 18(9): $1299-1315$

61. Lemperle G, Morhenn VB, Pestonjamasp V, Gallo R (2004) Migration studies and histology of injectable microspheres of different size in mice. Plast Reconstr Surg 113(5): 1380-1390.

62. Feretis C, Benakis P, Dimopoulos C, Dailianas A, Stamou KM, et al. (2003) Plexiglas polymethylmethacrylate Implantation: Technique, pre-clinical and clinical experience. Gastrointest Endoscopy Clin N Am 13(1): 167178.

63. Rupp TH, Lehman G (1994) Endoscopic antireflux techniques. Gastrointest Endosc Clin N Am 4: 353-68.

64. Bonavina L, Siboni S, Saino GI, Demetrio Cavadas, Italo Braghetto, et al. (2013) Outcomes of esophageal surgery, especially of the lower esophageal sphincter. Ann N Y Acad Sci 1300(1): 29-42.

65. Pandolfino JE, Krishnan K (2014) Clinical perspectives: Do endoscopic anti-reflux procedures fit in the current treatment paradigm of GERD? Clin Gastroenterol Hepatol 12(4): 544-554.

66. Lo WK, Mashimo H (2015) Critical assessment of endoscopic techniques for gastroesophageal reflux disease. J Clin Gastroenterol 49(9): 720-724.

67. Martin K, Emil S, Bernard C, Gaied F, Blumenkrantz M, et al. (2014) Dextranomer hyaluronic acid copolymer effects on gastroesophageal junction. J Pediatr Gastroenterol Nutr 58(5): 593-597.

68. Alshehri A, Emil S, Laberge JM, Elkady S, Blumenkrantz M, et al. (2014) Lower esophageal sphincter augmentation by endoscopic injection of dextranomer hyaluronic acid copolymer in a porcine gastroesophageal reflux disease model. J Pediat Surg 49(9): 1353-1359.

69. Rayess HM, Svider PF, Hanba C, Vivek Sagar Patel, Louis M Dejoseph, et al. (2017) A Cross-sectional Analysis of Adverse Events and Litigation for Injectable Fillers. JAMA Facial Plast Surg

70. Kirchin V, Page T, Keegan PE, Atiemo K, Cody JD, et al. (2017) Urethral injection therapy for urinary incontinence in women. Cochrane Database Syst 7: CD003881.

71. Lemperle G, Lemperle SM (2017) Injectable bulking agents for the treatment of stress urinary incontinence. SM Gerontol Geriatr Res 1(1): 1005.

72. Lehman GA (2003) Injectable and bulk-forming agents for enhancing the lower esophageal sphincter. Am J Med 115 (Suppl 3A): 188S-191S.

73. Lehman GA (2003) The history and future of implantation therapy for gastroesophageal reflux disease. Gastrointest Endoscopy Clin N Am 13(1): 157-165. 